\title{
Identifying user classes for shared and automated mobility services
}

\author{
Konstanze Winter ${ }^{1 *}$, Oded Cats ${ }^{1}$, Karel Martens ${ }^{2}$ and Bart van Arem ${ }^{1}$
}

\begin{abstract}
New forms of shared mobility such as free-floating car-sharing services and shared automated vehicles have the potential to change urban travel behaviour. In this paper, we identify potential user classes for these new modes. For this, a stated choice experiment on mode choice among a sample of the Dutch urban population has been conducted, which features free-floating car-sharing and shared automated vehicles next to private vehicles, bus, and taxi. The experimental design allows disentangling the effects of vehicle ownership, vehicle sharing and vehicle automation on the perceived utility of these modes. Further contributions lie in the identification of user classes for shared and automated mobility services and their potential migration from their current modes to the these services. Latent class choice models were estimated to capture the heterogeneity in these preferences among the respondents. The most explanatory mode choice model is obtained by estimating a 3-class nested logit model capturing the impact of vehicle ownership. The results show that higher educated and more time-sensitive respondents are more inclined than others to favour the (automated) car-sharing options. By simulating a scenario that directly compares car with free-floating car-sharing and taxi with shared automated vehicles, a migration analysis has been performed. This analysis shows that the preferences towards shared automated vehicles and freefloating car-sharing is highest for those currently combining car and public transport for their commute. Commuters using the car showed a high preference towards free-floating car-sharing, in particular as for the latter no parking fees are issued. Respondents currently commuting by public transport showed the lowest preference for the new modes.
\end{abstract}

Keywords: Free-floating Car-sharing, Shared automated vehicles, Stated choice, Latent-class choice Modelling

\section{Introduction}

The progress in the development of new vehicle technology and digital communication technology is leading to the emergence of new types of vehicles and mobility services. Two drivers of the possible diversification of mobility enabled by these developments are vehicle automation and urban vehicle sharing [18]. With the development of vehicle automation progressing rapidly and shared mobility gaining market shares, the question arises how the broad implementation of such concepts may change the transport service landscape. Car-sharing is mainly popular in Europe [28], while ride-sourcing has considerable

\footnotetext{
* Correspondence: m.k.ewinter@tudelft.nl

${ }^{1}$ Delft University of Technology, Delft, the Netherlands

Full list of author information is available at the end of the article
}

growth rates around the globe [23]. Nevertheless, both of these forms of shared mobility are still confined to niche markets and, with the exception of a few locations, are not available in large-scale systems with high coverage or accessibility. For this reason, such services are, so far, mainly used by quite specific user groups: e.g. for car-sharing systems in Europe it has been shown that these are mainly used by young people living in cities, mainly men and people with a higher education level [7]. Similar characteristics were found for the users of ride-sourcing services [33]. These characteristics are often associated with socalled "early adopters" of such new mobility services [1].

How travel behaviour of other groups might change in the light of new shared mobility services available on a large scale remains uncertain, as long as these services do not have high coverage. The primary source of 
information on traveller's choices for these new mobility services is therefore still stated preference experiments. This study contributes to building up a better understanding of the potential migration from the current modes to the new, shared transport services enabled by the developments in digital communication technology. In particular, a mode choice model is estimated that includes current motorized modes as well as Free-Floating Car-sharing (FFCS) and Shared Autonomous Vehicles (SAV). In contrast to station-based car-sharing, there is no designated infrastructure linked to this form of mobility and users can freely choose their departure time as well as their destination [16]. SAV can be described as a form of FFCS, in which vehicles travel autonomously, i.e. with no driver on board, transporting at least one passenger to its final destination. The required level of driving automation of such vehicles, therefore, has to be level 4 or 5 [27]. For FFCS and SAV, the act of vehicle sharing is a sequential one, as a ride is not shared with unknown passengers. These modes offer therefore the same level of privacy as the private car. SAV bear a resemblance to current taxi services and ride-sourcing services in the way they are operated and are thus also referred to as autonomous taxis or aTaxi [18].

The number of stated-choice experiments comparing free-floating car-sharing with other motorized modes is not large, and the findings of these studies are not always consistent: while some examples show that older people are more likely to choose one-way car-sharing than younger ones [14, 32], shows the majority of stated-preference experiments that it is the younger ones who are most likely to switch to such car-sharing services. As summarized by Spurlock et al. [29], the most commonly observed user characteristics for shared mobility services are, that they are younger, richer, more educated and have fewer children than the average population.

In the overview of the first stated choice experiments featuring automated vehicles $[6,17]$, it becomes apparent that only a few of these studies focus on the automated vehicle as a shared mode. In a stated choice experiment conducted among an Australian online panel, sequentially shared and simultaneously shared automated vehicles showed to be perceived as two distinctive modes by the participants, with a strong preference for sequentially shared SAV over simultaneously shared SAV [25]. Conversely, a stated choice experiment conducted among a German online panel found that the simultaneously shared SAV is preferred over the sequentially shared one [24] - the authors suggest that this could be attributed to the lower costs associated with the simultaneously shared option. In regard to potential early adopters of SAV, the following demographics have been found to describe people with a higher preference for SAV: people currently using public transport or using multiple modes frequently
[25], younger people $[19,25]$, men [19] and people with a higher income or a higher degree of education $[4,5,6$, 19]. In regard to the current commuting behaviour, it has been shown that people currently commuting long distances by car and those who experience usually short parking-search times are less likely to use shared automated vehicles [5].

Estimating mode choice models for mode alternatives that are not widely available or do not exist yet remains a challenge. However, the need for models incorporating shared (automated) mobility services is rising with their rapid introduction. But a conclusive picture on mode choice in the era of (automated) car-sharing cannot be drawn at this point, as any conducted mode choice experiment featuring these mode alternatives is merely a snapshot in time of the current perception of these modes. It remains therefore important to conduct such experiments continuously over time, as well as for the different operational specifications of shared (automated) mobility services, different regions, different trip purposes and combinations of mode choice options. This research contributes to these efforts by conducting a mode choice experiment featuring a combination of shared mobility options that has not been tested so far. The experimental design, detailed in the following section, allows disentangling various features related to new mobility services. The focus of the analysis is put on the differences in mode preference, or taste heterogeneity, in order to identify potential user classes for these modes. Our attention is, in particular, turned to the current mode choice as a predictor. The main contributions of this paper can be summarized as the following:

1. increasing our understanding of the potential migration from the current modes to the new, shared transport services;

2. comparing preferences for automated and nonautomated on-demand transport services;

3. identifying user classes for shared and automated mobility services.

The remainder of this paper is structured as follows: The methodological specifications of the stated choice experiment are shown in section 2 . In section 3 , a latent class choice model for mode choice preferences is described and the estimated results are presented and analysed. In section 4 , the results are discussed and an outlook on further research needs is given.

\section{Stated choice experiment}

In order to determine how mode choice behaviour could change with the introduction of Free-Floating Carsharing (FFCS) and Shared Autonomous Vehicles (SAV), we conducted a stated choice experiment. For this, an 
online survey was distributed, using the online survey software Collector. Participants were asked to make a choice between various mode choice options in 9 choice situations. Additionally, socio-economic parameters have been collected on an individual and household level, as well as the participants' familiarity with car-sharing and ride-sourcing services.

\subsection{Description of the choice situation}

For the choice experiment, a trip was described as a commuting trip to a fictitious workplace or educational institution in the respondents' home town. The trip distance was set to be approximately $8 \mathrm{~km}$. This is just above the threshold value of $7.5 \mathrm{~km}$, below which the bike is the most preferred mode in the Netherlands and above which more than three-quarters of all trips are performed by car [26]. This trip length has been selected in order to be able to analyse the preference of SAV as an alternative to private cars in an urban commute. The choice experiment refers to commuting, as it is an important trip purpose in the Netherlands (and elsewhere), in particular during rush hours [22].

In each choice situation, five travel mode alternatives were presented to the participants: privately owned vehicles (car), free-floating car-sharing (FFCS), taxis (taxi), a direct bus line (bus) and shared automated vehicles $(S A V)$. Respondents were familiarised with the concepts of FFCS and SAV by providing the descriptions shown in Fig. 1. They were free to choose any mode option irrespective of their current situation in terms of car ownership and driving license possession.

\subsection{Design of stated choice experiment}

Following the argumentation of Walker et al. (2015) [30], an orthogonal design has been selected as the most suitable layout of the stated choice experiment. The design was generated using 54 choice tasks, blocked in six groups by using the software Ngene. The five modealternatives are characterized by six attributes, each with three levels (Table 1). The attribute levels in terms of travel time and travel costs were chosen to be similar to travel times and costs Dutch commuters commonly experience.

\section{Results}

\subsection{Respondent panel and sample composition}

The stated choice experiment has been conducted in April 2016 among 840 members of an online panel (data set available at: https://doi.org/10.4121/uuid:4ac4d7b7c8b0-42ec-a096-55a4f1837585). The participants were older than 18 years old and originated from the four largest cities of the Netherlands (Amsterdam, The Hague, Rotterdam, and Utrecht). In order to capture the commuting population, only respondents studying or working more than $12 \mathrm{~h}$ per week (employed, self-employed or as volunteers) were included. After excluding inconsistent answers, the final data set has been reduced to 796 responses (95\% of the total sample). This sample

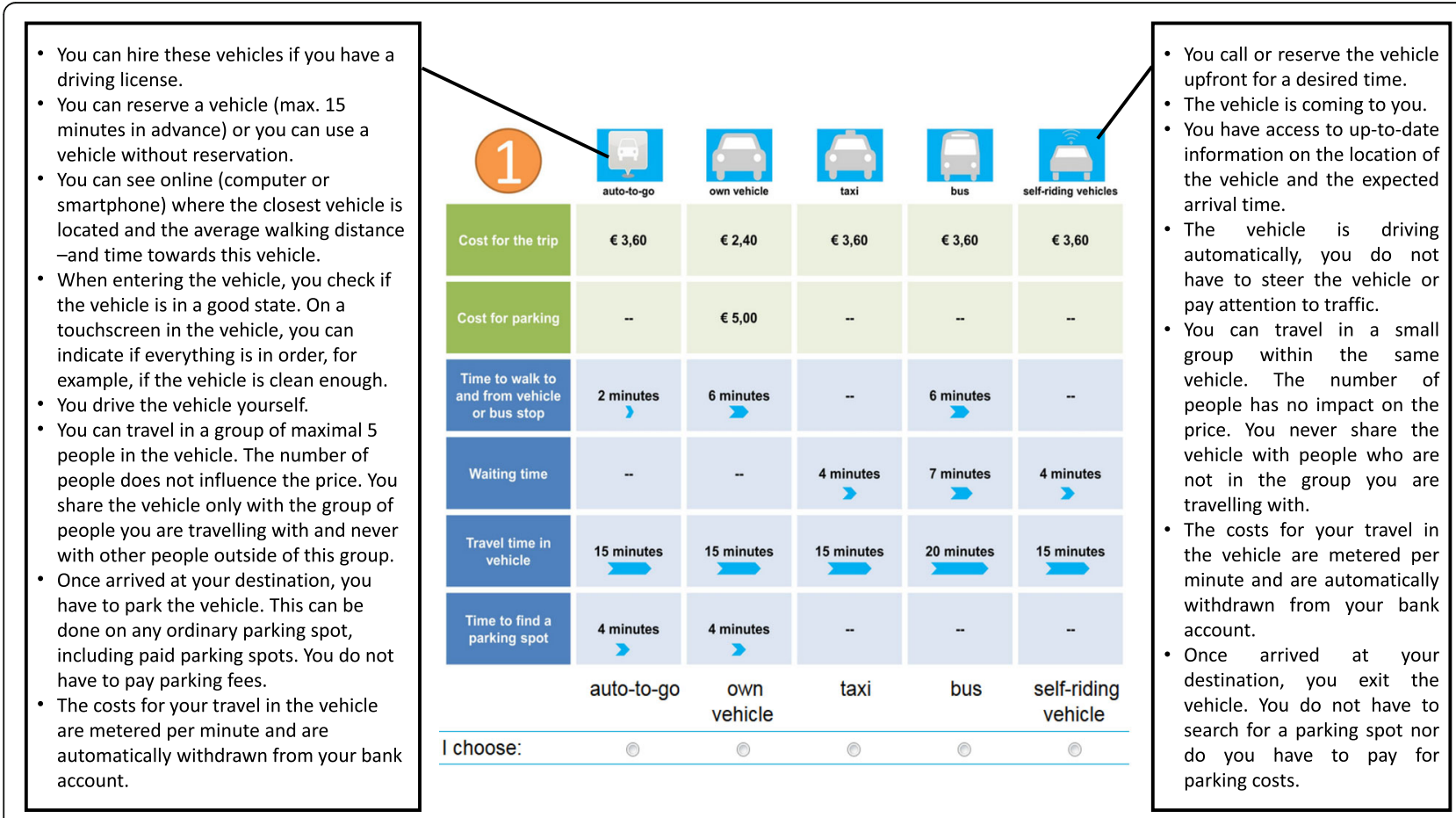

Fig. 1 Description of FFCS and SAV as presented to the participants (translated from Dutch) 
Table 1 Mode attributes and attribute levels presented in the choice experiment. N.A. stands for 'not applicable'

\begin{tabular}{llllll}
\hline & car & FFCS & bus & taxi & SAV \\
\hline Travel costs [in Euro] & $1.2 ; 2.4 ; 3.6$ & $1.2 ; 2.4 ; 3.6$ & $1.2 ; 2.4 ; 3.6$ & $3.6 ; 4.2 ; 4.8$ & N.A. \\
Parking costs in Euro] & $0 ; 2.5 ; 5$ & N.A. & N.A. & N.A. \\
Access and Egress Time [in min] & $2 ; 4 ; 6$ & $6 ; 10 ; 14$ & $2 ; 6 ; 10$ & N.A. \\
Waiting Time [in min] & N.A. & N.A. & $1 ; 4 ; 7$ & $1 ; 4 ; 7$ & N.A. \\
In-Vehicle Time [in min] & $15 ; 20 ; 25$ & $15,20,25$ & $20 ; 25 ; 30$ & $15 ; 20 ; 25$ & N.A. \\
Parking search Time [in min] & $1 ; 4 ; 7$ & $1 ; 4 ; 7$ & N.A. & N.A. \\
\hline
\end{tabular}

size is representative of the working population of the four cities, which has a population size of 1,119,300 [12] on a confidence interval of $99 \%$ and a margin of error of $5 \%$. The main characteristics of the respondents in this data set are presented in Table 2.

The distribution of gender, income, and access to at least one vehicle per household are all similar to the Dutch national average $[9,10]$. The sample distribution does however not represent the national modal share for commuters. Around $60 \%$ of all workers commute by private car in the Netherlands [11], while the share of commuters using (partly) public transport lies around 13\% [20]. The findings in the collected sample differ in this, as only $29 \%$ of the respondents indicated that they exclusively commute by car, while $35 \%$ of the respondents indicated that they commute (partly) by public transport, as shown in Fig. 2.

\subsection{Mode choice model estimation}

We estimated the model as a nested logit model with latent classes. For the mathematical formulation of such a hybrid choice model, we point to the work of Wen et al. [31]. This model has been selected for two reasons: (1) the modes presented in the choice experiment share unobserved attributes and (2) a strong heterogeneity in taste has been observed among the respondents. The implications of this are discussed in the following.

\subsubsection{Introducing nested logit models to account for shared unobserved attributes}

To account for unobserved correlations related to the dimensions between the mode alternatives, we estimated nested logit (NL) models for various nesting structures related to car ownership, vehicle automation, the level of privacy in the vehicle, driving tasks and the demand responsiveness of a mode. The lowest log-likelihood values and minimum Bayesian Information Criterion (BIC) values were obtained for the nested logit model taking car ownership into account, corroborating the findings in [19]. The log-likelihood ratio test shows a significantly better modal fit on a $99.9 \%$ confidence level for this model, and all nest coefficients lie within the required range $[0,1]$. Conceptually, this model takes into account that the mode-option car is privately owned, while FFCS, taxi, bus, and $S A V$ are shared modes.

Table 2 Main socio-demographic characteristics of respondents

\begin{tabular}{|c|c|}
\hline Characteristic & Total number (percent) [class] \\
\hline Respondents: & 796 \\
\hline Mean age (standard deviation): & $41.78(14.1)$ \\
\hline Respondents per age classes (in percent) [class]: & $\begin{array}{l}204(25.6 \%)[18-29] ; 168(21.1 \%)[30-39] ; 153(19.1 \%) \\
{[40-49] ; 159(20.0 \%)[50-59] ; 112(14.1 \%)[60-80]}\end{array}$ \\
\hline Gender: male; female (in percent): & 399 (50. 1\%); 397 (49.9\%) \\
\hline Driving license holder (in percent): & $684(85.9 \%)$ \\
\hline Household with children (in percent): & $215(27.1 \%)$ \\
\hline $\begin{array}{l}\text { Household has access to at least one vehicle; and more } \\
\text { than one vehicle (in percent): }\end{array}$ & $598(75.1 \%) ; 168(21.1 \%)$ \\
\hline Highest level of education (in percent) [class]: & $\begin{array}{l}108 \text { (13.6\%) [Primary school and lower education]; } 317 \text { (39.8\%) } \\
\text { [High school or mid-level education]; } 370 \text { (46.5\%) [higher education] }\end{array}$ \\
\hline Yearly household income (in percent) [class]: & $\begin{array}{l}191(24.0 \%)[0-30,000 \text { Euro]; } 321 \text { (40.3\%) [30,000-60,000 Euro]; } 150 \\
\text { (18.8\%) [more than 60,000 Euro]; } 134(16.8 \%) \text { not reported }\end{array}$ \\
\hline $\begin{array}{l}\text { Households with at least one household member subscribed } \\
\text { to a car-sharing service in general and to a free-floating car- } \\
\text { sharing service in particular (in percent): }\end{array}$ & $76(9.1 \%)$ [Car-Sharing in general]; 24 (3.1\%) [Free-Floating Car-Sharing] \\
\hline Uber user and/or chauffeur (in percent): & $97(12.2 \%)$ \\
\hline
\end{tabular}




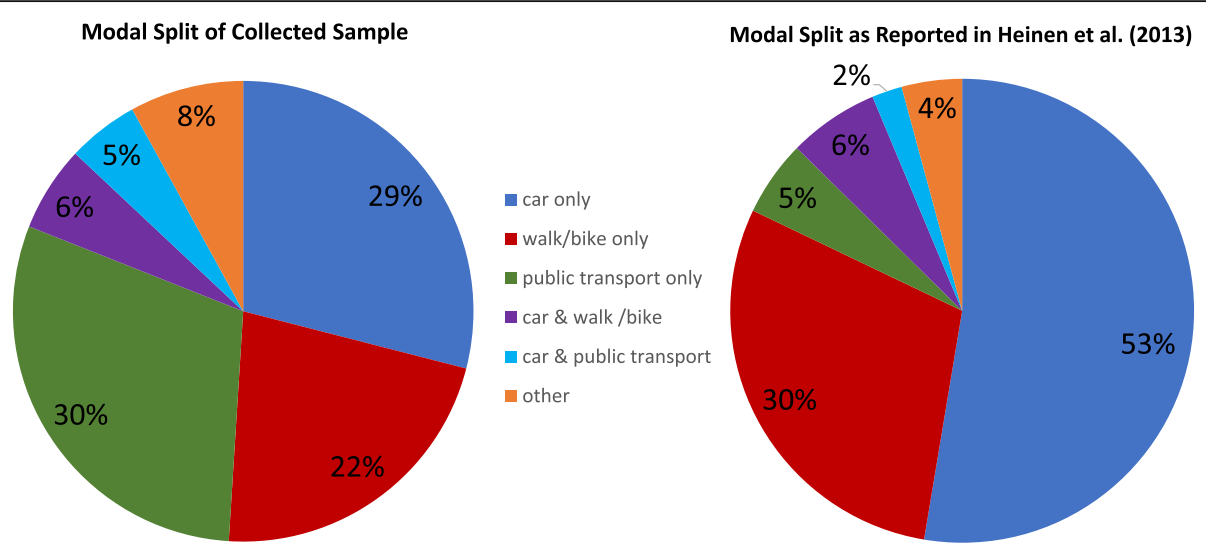

Fig. 2 Commuting modal split of the collected sample (left) and the Dutch average (right)

\subsubsection{Introducing latent classes to account for decision rule heterogeneity}

In the collected response set, $24 \%$ of all respondents selected exclusively one mode throughout all nine choice questions. A large share of respondents showing lexicographic preferences is not an uncommon observation in stated choice experiments with labelled alternatives, especially in the presence of new or unknown alternatives [21]. Comparable stated-choice experiments have shown before that approximately a quarter of the respondents are non-traders (see e.g. [13, 19]). Introducing latent classes to the model is an appropriate means to capture non-trading behaviour [3].

A three-class model has been selected, based on its fitting statistics and it yielding meaningful and significant nesting and class membership parameters. The class membership is characterized by four categories: age group (below or above 40), education (low and mid-level education or high-level education), currently commuting by private vehicle, and not public transport (true or false) and currently commuting by public transport, and not a private vehicle (true or false). Introducing these nested classes further improves the model fit of the nested logit model on a $99.9 \%$ confidence level for the log-likelihood ratio test, and the $\mathrm{BIC}$ value of the model with latent classes is significantly lower $(\Delta-\mathrm{BIC}=442)$.

\subsubsection{Estimated parameters values}

The nested logit model with latent classes was estimated with the dedicated software BIOGEME [8], using the optimization algorithm "BIO" intrinsic to the software. The estimated parameter values for the panel response set collected from 796 respondents (7164 total number of observations) are shown in Table 3. The model consists of 41 variables, has a rho-square value of 0.32 and a final log-likelihood of -7769 .
The probabilities of belonging to a class are distributed in the following way: $63 \%$ for Class $1,20 \%$ for Class 2 and $17 \%$ for Class 3 . In Fig. 3, the composition of the three classes in regard to the socio-economic categories is shown in comparison to the sample average. The underlying colour scheme indicates the class deviation from the sample average, with red showing an underrepresentation and blue an overrepresentation compared to the sample average within one socio-economic category.

Not just the mode preference, as discusses in section 3.2.2, but also the sensitivity to cost and travel time can be the reason for discontinuous decision making. Respondents who have a larger probability to fall into Class 1 and Class 2 are more cost-sensitive than those with a larger probability to fall into Class 3. By modelling latent classes, these sorts of lexicographic preferences are captured to some extent. Based on these observations and the class mean values, the following class descriptions are made:

- "Brisk Sharers" (class 1): This majority group (57\%) prefers shared modes over private cars, as indicated by the strong and positive alternative specific constants $(A S C)$ for all shared modes. Brisk Sharers show a much stronger sensitivity towards an increase in travel time than Public Transport Enthusiasts (class 2). Brisk Sharers have a higher likelihood to be younger than 40 years old. This age group consists mainly of the generational cohort known as the "millennials" or "generation Y" (born in the 1980s -1990s), who tend to be less caroriented than previous generations and be more open towards new means of transportations $[2,15]$.

- "Public Transport Enthusiasts" (class 2): This group is the second largest group (20.3\%) and represents individuals who currently tend to commute by public transport, and not by private car. They are more price-sensitive and much less sensitive to 
Table 3 Estimated coefficients, class membership parameters and nesting parameters

\begin{tabular}{|c|c|c|c|c|c|c|c|}
\hline \multicolumn{2}{|c|}{$\begin{array}{l}\text { Class } \\
\text { (class-membership probability in \%) }\end{array}$} & \multicolumn{2}{|c|}{$\begin{array}{l}\text { Class } 1 \text { ( } 62.9 \%) \text { : } \\
\text { "Brisk Sharers" }\end{array}$} & \multicolumn{2}{|c|}{$\begin{array}{l}\text { Class } 2 \text { (20.26 \%): } \\
\text { "Public Transport Enthusiasts" }\end{array}$} & \multicolumn{2}{|c|}{$\begin{array}{l}\text { Class } 3 \text { (16.79\%): } \\
\text { "Car Captives" }\end{array}$} \\
\hline \multicolumn{8}{|c|}{$\begin{array}{l}\text { Utility Coefficients } \\
\text { value }[\mathrm{p}-\mathrm{value}]:{ }^{* * *}=\text { significant at } 99 \% \mathrm{Cl},{ }^{* *}=\text { significant at } 95 \% \mathrm{Cl},{ }^{*}=\text { significant at } 90 \% \mathrm{Cl} \\
\text { N.A.: not applicable, constrained by specification }\end{array}$} \\
\hline \multicolumn{2}{|c|}{$\mathrm{ASC}_{\mathrm{FFCS}}$} & 1.09 & {$[0.00]^{* * *}$} & 1.18 & {$[0.00]^{* * *}$} & -2.85 & {$[0.00]^{* * *}$} \\
\hline \multicolumn{2}{|l|}{$\mathrm{ASC}_{\mathrm{PT}}$} & 0.816 & {$[0.00]^{* * *}$} & 1.61 & {$[0.00]^{* * *}$} & -2.71 & {$[0.00]^{* * *}$} \\
\hline \multicolumn{2}{|l|}{ ASC $_{S A V}$} & 1.30 & {$[0.00]^{* * *}$} & 1.22 & {$[0.00]^{* * *}$} & -2.92 & {$[0.00]^{* * *}$} \\
\hline \multirow{10}{*}{$\mathrm{ASC}_{\mathrm{taxi}}$} & & 1.21 & {$[0.00]^{* * *}$} & 1.23 & {$[0.00]^{* * *}$} & -2.63 & {$[0.00]^{* * *}$} \\
\hline & $\beta_{\text {cost_parking }}$ & -0.272 & {$[0.00]^{* * *}$} & -0.278 & {$[0.00]^{* * *}$} & -0.127 & {$[0.06]^{*}$} \\
\hline & $\beta_{\text {cost }}$ & -0.218 & {$[0.00]^{* * *}$} & -0.147 & {$[0.03]^{* *}$} & -0.010 & {$[0.40]$} \\
\hline & $\beta_{\text {walk }}$ & -0.02 & {$[0.00]^{* * *}$} & N.A. & -- & N.A. & -- \\
\hline & $\beta_{\text {wait }}$ & -0.028 & {$[0.00]^{* * *}$} & N.A. & - & N.A. & - \\
\hline & $\beta_{\mathrm{IVT}, \mathrm{FFCS}}$ & -0.025 & {$[0.00]^{* * *}$} & -0.005 & {$[0.09]^{*}$} & -0.02 & {$[0.41]$} \\
\hline & $\beta_{\mathrm{IVT}, \mathrm{SAV}}$ & -0.025 & {$[0.00]^{* * *}$} & & & & \\
\hline & $\beta_{\mathrm{IVT}, \text { taxi }}$ & -0.031 & {$[0.00]^{* * *}$} & & & & \\
\hline & $\beta_{\text {IVT,bus }}$ & -0.012 & {$[0.00]^{* * *}$} & & & & \\
\hline & $\beta_{\mathrm{IVT}, \text { parkingSearch }}$ & -0.011 & {$[0.01]^{* *}$} & -0.068 & {$[0.00]^{* * *}$} & N.A. & -- \\
\hline
\end{tabular}

\section{Class Membership}

value [p-value]: ${ }^{* *}=$ significant at $99 \% \mathrm{Cl},{ }^{* *}=$ significant at $95 \% \mathrm{Cl},{ }^{*}=$ significant at $90 \% \mathrm{Cl}$

\begin{tabular}{|c|c|c|c|c|c|c|}
\hline intercept $\delta$ & 0.00 & (fixed) & -0.69 & {$[0.00]^{* * *}$} & -1.68 & {$[0.00]^{* * *}$} \\
\hline 18 to 39 years old & 0.00 & (fixed) & -1.28 & {$[0.00]^{* * *}$} & -0.992 & {$[0.00]^{* * *}$} \\
\hline high education & 0.00 & (fixed) & 0.11 & {$[0.63]$} & -0.517 & {$[0.03]^{* *}$} \\
\hline currently private car for commuting & 0.00 & (fixed) & -1.79 & {$[0.00]^{* * *}$} & 1.77 & {$[0.00]^{* * *}$} \\
\hline currently public transport for commuting & 0.00 & (fixed) & 1.09 & {$[0.00]^{* * *}$} & -0.65 & {$[0.23]$} \\
\hline
\end{tabular}

\section{Nest Coefficients}

scale parameter [p-value]: ${ }^{* * *}=$ significant at $99 \% \mathrm{Cl},{ }^{* *}=$ significant at $95 \% \mathrm{Cl},{ }^{*}=$ significant at $90 \% \mathrm{Cl}$

\begin{tabular}{lllllll}
$\mu_{1}$ & 1.00 & (fixed) & 1.00 & (fixed) & 1.00 & (fixed) \\
$\mu_{2}$ & 3.91 & {$[0.00]^{* * *}$} & 6.90 & {$[0.04]^{* *}$} & 4.55 & {$[0.37]$} \\
\hline
\end{tabular}

The parameter for modes that are not privately owned has a scale parameter of $\mu_{2}=3.91$, leading to a nest coefficient of $\mu / \mu_{2}=1 / 3.91=0.26$ for Class 1 , and to nest coefficients of 0.15 and 0.22 for Class 2 and Class 3, respectively. For all classes, the nest coefficient lies thus between 0 and 1 , which is a requirement for a valid nesting structure

\begin{tabular}{|l|c|c|c|c|}
\cline { 2 - 5 } \multicolumn{1}{l|}{} & $\begin{array}{c}\text { Sample } \\
\text { Average }\end{array}$ & $\begin{array}{c}\text { "Brisk Sharers" } \\
\mathbf{( 6 2 . 9 \% )}\end{array}$ & $\begin{array}{c}\text { "Public Transport } \\
\text { Enthusiasts" } \\
\mathbf{( 2 0 . 3 \% )}\end{array}$ & $\begin{array}{c}\text { “Car Captives" } \\
\mathbf{( 1 6 . 8 \% )}\end{array}$ \\
\hline 18 to 39 years old & $47 \%$ & $57 \%$ & $33 \%$ & $25 \%$ \\
\hline high educational level & $47 \%$ & $50 \%$ & $44 \%$ & $37 \%$ \\
\hline $\begin{array}{l}\text { commute by private car (and } \\
\text { not public transport) }\end{array}$ & $37 \%$ & $35 \%$ & $6 \%$ & $81 \%$ \\
\hline $\begin{array}{l}\text { commute by public } \\
\text { transport (and not private } \\
\text { car) }\end{array}$ & $25 \%$ & $22 \%$ & $53 \%$ & $4 \%$ \\
\hline
\end{tabular}

Fig. 3 Class membership probability per included socio-economic variable 
changes in in-vehicle-time than Brisk Sharers, but show an equally strong preference for shared modes in contrast to the private car. Public Transport Enthusiasts have a higher likelihood to be older than 40 years old.

- "Car Captives" (class 3): This small group (16.8\%) consists of individuals who currently commute by private car. This group shows a strong preference towards the private car in the choice experiment as well, as indicated by the strong negative ASC for all shared modes. Car Captives are non-traders who can be characterized as mode-captives favouring private cars. In terms of their socio-economic profile, they tend to be older and less educated than the sample average.

\subsubsection{Mode preferences}

As can be seen in Table 3, not all variables presented in the mode choice experiment were included in the final model, in particular, the in-vehicle-time for the private car proved to be insignificant, and showed an unexpected positive sign. This variable has been excluded from the model under the consideration that the preference for travelling in private cars is captured in the strong values for the alternative specific constants (ASC) present in all three classes. These indicate that participants disregarded to a certain extent other parameters detailing the trip presented to them in the choice experiment. This is true in particular for the class of the Car Captives, for which also the coefficient for the invehicle-time and the travel costs are not significant. This class mainly captures respondents with lexicographic preferences making choices irrespective of the attributes and attribute levels, as discussed in the previous section.

3.2.4.1 Travel costs and parking costs No significant difference could be observed for the perception of travel costs for the different modes, and therefore the coefficient for the travel costs is modelled as a mode-generic one in all classes. The cost of parking, which only occurred in the case of the private car, is penalized in all three classes stronger than the cost of travelling. This is particularly true for the class of the Car Captives, for which this parameter has proven to be the only one out of the parameter set detailing the trip, to significantly have impacted the choices.

3.2.4.2 Travel time In terms of time-related parameters, the Brisk Sharers perceive a significant difference between the in-vehicle time for the different shared modes. This class penalizes spending time travelling in the bus the least, followed by the in-vehicle-times in SAV and FFCS, the lowest preference is shown for the in-vehicle time spent in taxis. The strong difference in the preference for SAV and taxi is also present in the alternative specific constants $\mathrm{ASC}_{\mathrm{taxi}}$ and $\mathrm{ASC}_{\mathrm{SAV}}$. This reveals the perception of the utility of vehicle automation in itself, as taxi and SAV have been presented to be equal in regard to the service they provide apart from one being a self-driving vehicle and the other being driven by a taxi-chauffer. The class of Brisk Sharers prefers travelling in the self-driving vehicle, with the difference in preference being mainly captured in the alternative specific constants and thus not only relating to the time spent in the vehicle.

Differing from the other two classes, the Brisk Sharers also consider the access/egress walking time and waiting time in their choice, which is in this class generally penalized slightly stronger than the in-vehicle-time spent in the shared modes. For the classes of the Public Transport Enthusiasts and the Car Captives, a mode generic coefficient for all shared modes proved to be the most descriptive. It is remarkable that, even while the invehicle time does not majorly influence the mode choice behaviour of the Public Transport Enthusiast, there is a strong aversion towards the time spent searching a parking spot.

\subsection{Model application: modal migration analysis}

In order to get a better understanding of the estimated mode choice preferences per class, the model is applied to a specific scenario by simulation (based on 10,000 draws). In this scenario, the attribute levels have been set equal for car and FFCS, as well as for taxi and SAV, to allow a direct comparison between these modes respectively. The applied values are shown in Table 4.

The obtained modal shares shown in Table 4 are explored in more detail in a migration analysis, showing the choice probabilities itemized for the current commuting modes used by the participants of this study. In Fig. 4, the migration flows are shown from the current modes (left) to the mode choices based on the estimated model applied to the scenario (right). The width of each flow towards a mode is directly proportional to the

Table 4 Attribute levels applied in the scenario and resulting choice probability per mode

\begin{tabular}{llllll}
\hline & car & FFCS & bus & taxi & SAV \\
\hline Travel cost [in Euro] & 2.4 & 2.4 & 2.4 & 3.6 & 3.6 \\
Parking cost [in Euro] & 0 & N.A. & N.A. & N.A. & N.A. \\
Access/Egress time [in minutes] & 6 & 6 & 6 & N.A. & N.A. \\
Waiting time [in minutes] & N.A. & N.A. & 4 & 4 & 4 \\
In-vehicle-time [in minutes] & 20 & 20 & 20 & 20 & 20 \\
Parking-search time [in minutes] & 1 & 1 & N.A. & N.A. & N.A. \\
& $\downarrow$ & $\downarrow$ & $\downarrow$ & $\downarrow$ & $\downarrow$ \\
Estimated Choice Probability & $24 \%$ & $21 \%$ & $25 \%$ & $14 \%$ & $16 \%$ \\
\hline
\end{tabular}



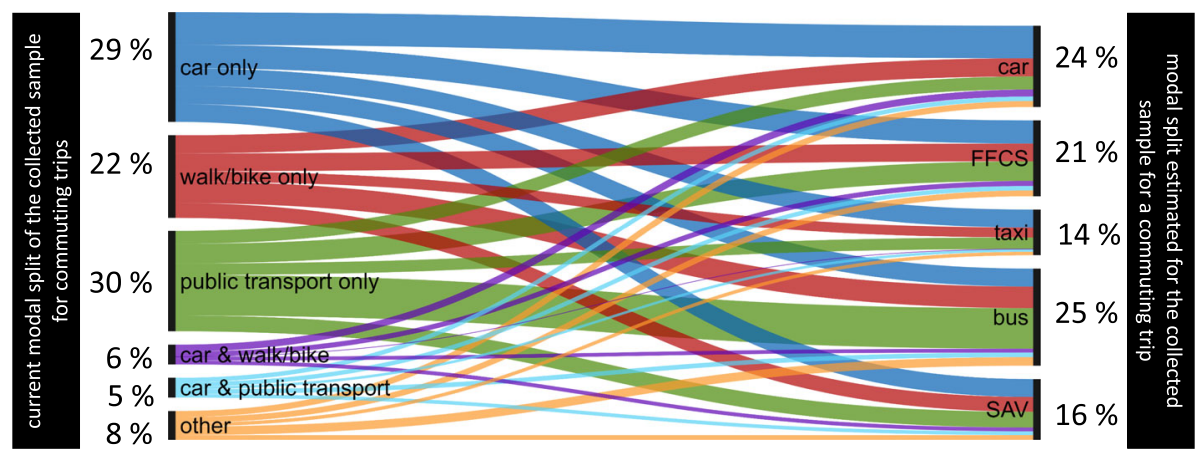

Fig. 4 Estimated mode migration patterns: current (left) and estimated (right) market shares per commuting mode(s)

estimated probability for a commuter group to choose this mode. So can be seen that the largest contribution to the estimated modal share of private cars stems from commuters also currently using a private car, which have an estimated probability of $30 \%$ to choose a private car in this scenario. Similarly, the largest contribution to the estimated modal share of the bus stems from current public transport users, with an estimated probability of $37 \%$ of choosing public transport. Respondents indicating that they currently commute by combining private car and active modes (walk, cycle) show the same mode choice probabilities as those indicating to commute only by car.

The model allows taking a closer look at the effect of vehicle sharing and vehicle automation, by directly comparing car with FFCS and taxi with $S A V$ respectively. Those currently commuting by combining car and public transport have an estimated probability of $18 \%$ to choose $S A V$, which is a higher probability than in other commuter groups. Those currently commuting by public transport have the lowest probability of choosing $S A V$ (14\%). When comparing the choice probabilities of $S A V$ and taxi, it can be seen that all commuter groups, except those using the mainly the car, clearly favour $S A V$ over taxi. The probability for choosing FFCS is for all commuters higher than for $S A V$, ranging from $18 \%$ for public transport users and $22 \%$ for those currently taking the car or combing car and walking/cycling. The latter group has an equal preference for car and FFCS. However, for all other groups is the preference for FFCS much stronger than the one for car, the strongest difference can be observed for those currently combing the car and public transport for commuting.

\section{Discussion and conclusion}

Currently, on-demand transport services are labour-cost intensive and therefore provided mainly to the elderly, passengers with special needs or in rural areas. With the introduction of digitalized mobility forms and services, on-demand transport can be offered on a larger scale against limited costs, expanding the pool of potential users. In this paper, it is analysed how the introduction of free-floating car-sharing and shared automated vehicles on a large-scale could change mode preferences for different user groups.

\subsection{Preferences for shared (automated) modes}

While stated choice experiments are an opportunity to capture preferences about novel alternatives, they bear the risk that uncertainty, expectations and current risk perception are influencing the choices made and respondents might develop a different attitude towards these modes once they become more familiar with them [25]. Therefore, the outcome of this experiment can only be an indication of the current perception of the utility of the new modes, and not a forecast of mode preference once the presented modes might become broadly available. Bearing this in mind, the results of the analyses offer the following insights in terms of the perception of shared and shared automated vehicles:

\section{- Car commuters are open for using shared} mobility services providing a similar experience to their current mode, but they are not charmed by vehicle automation The findings of the migration analysis suggest that commuters who currently mainly use a private car show a high preference for FFCS. The migration to FFCS from this group can be further amplified when charging parking fees (which are not included in the simulated scenario), considering that the class of Car Captives shows a strong aversion towards parking costs.Commuters taking the car show a lower preference for the other modes of shared mobility included in the choice experiment. This group perceives the utility of $S A V$ marginally lower than the utility of taxi, indicating this group does not see vehicle automation to be an added value in itself. Car Captives have been found before to be less likely to switch to SAV [19]. 
- Commuters currently combining car and public transport are the most enthusiastic about shared (automated) mobility services Commuters currently opting for a combination of car and public transport for their commute are the most enthusiastic about FFCS and SAV. This group shows the strongest preference towards these modes and also shows the strongest difference in the perceived utility between car and FFCS, and the second-strongest difference in the perceived utility between taxi and $S A V$. This indicates that the added value of the new shared (automated) mobility service is the strongest for this group. A possible reason for this could be that this group has mobility needs that are neither met by a car or public transport services alone, and that FFCS and $S A V$ are perceived to close this gap by combining the advantages of a car and public transport services.

- Public transport users are the least impressed with on-demand shared (automated) mobility services For commuters currently using public transport, the introduction of shared automated vehicles increases the perceived utility for ondemand door-to-door services, as for this group a higher probability for choosing $S A V$ than for choosing taxi has been estimated. However, no other group has lower mode choice probabilities for FFCS and $\mathrm{S} A V$ than this group. The latent class analysis shows that Public Transport Enthusiasts have a higher probability to feature older respondents and respondents having a lower level of education, and captures those that are more cost-averse rather than time-loss-averse. This group of people has been found before to be less likely to opt for automated vehicles [17].

- Young and time-sensitive commuters are the most appreciative of vehicle automation The class of participants showing the greatest enthusiasm for FFCS and SAV are captured in the class of the Brisk Sharers (63\% of the sample), who also show a strong preference for travelling in $S A V$ over taxi. This class is characterised by being younger and more educated than the sample average.

- Commuters currently cycling or walking see an added-value in vehicle automation The group of commuters currently walking or cycling to work shows the strongest difference in the perception of $S A V$ and taxi. It should be noted that the mode choice experiment did not incorporate active mode options and thus forced this group to select exclusively between motorized modes. The estimated model therefore merely captures the difference in mode perceptions between the included modes, and not the perceived utility in relation to the modes this group is currently using. The findings in this study largely corroborate the image of the "early adopters" of shared (automated) vehicles sketched in previous studies, as summarized in the introduction. The main difference is that in this study neither gender nor the number of children significantly improved the clustering of the observed choices. Instead, the current mode choice showed to be a more reliable predictor for the collected sample. Different from Krueger et al. [25], the public transport users included in our study showed the lowest preference for SAV. In fact, survey respondents who combine public transport use and private car for their commuting trips showed the highest preference for SAV, as well as for FFCS. Indeed, our study showed that multimodal commuters and those using active modes (walking or biking) have the highest preference for the new modes. Therefore we suggest adding these characteristics to the image of an "early adopter" of shared (automated) mobility services.

\subsection{Policy implications}

The discussion around the description of the "early adopter" of new digitalized mobility forms and services does not include consequences for "late adopters". From the results of this study, as well as the findings in similar studies, it can be deducted that such modes primarily meet the travel needs of a group that currently already has a high degree of flexibility in mode choices, while those currently dependent only on a private car or on public transport show the lowest preferences for the ondemand transport services included in the choice experiment. The potential added value of FFCS and SAV differs for these two distinct groups. Car users, even if they are captive users, typically already have a fast and comfortable mode at their disposal. For this group, the study points to a clear trigger that could support the switch from using the private car to shared options: the "nuisance of parking". Both the time having to spent on searching a parking spot and the costs of parking influenced the expressed mode preferences significantly. Ambitious urban parking management that makes room for shared mobility services and limits (free) parking possibilities for private cars has thus the potential to play an important role in making the shared services a success story, also among this user group. Research corroborates this, as a number of studies show that parking availability and costs are prime factors influencing the use of car-sharing systems [16] and parking search time impacts the willingness to use shared automated vehicles [5].

The situation for the second group, consisting of public transport users, is quite different however. These 
respondents showed the lowest preference for the new transport modes in our study. This may in part be because of a general satisfaction with the quality of public transport or it may be because of the costs related to new digitalized mobility forms. If the latter is the case, it implies that such new modes will do little to enhance the choice set for this user group or for enhancing the ease with which they can get around. This raises concerns, as it is especially the group of public transport dependents who are at risk of transport poverty. Policy interventions that reduce the costs of using FFCS and SAV may thus be necessary if these new mobility forms are to enhance the inclusiveness of the transport system.

\subsection{Study limitations and outlook}

The limitations of this study are primarily related to the inclusion of unknown alternatives in the choice experiment, potentially leading to a hypothetical bias in the context of estimating the willingness-to-pay. The estimated model therefore only offers a first step in quantitatively analysing current preferences towards FFCS and SAV, but does not represent a full mode choice model for an era where these modes might become widely available. This study by no means provides conclusive evidence on the preferences of the different user classes towards new shared and automated mobility services. The choice experiment has been complex in the compositions of the choice alternatives, so various important aspects could not be included in order to not burden the respondents with an overload of information and options. Future studies could extend the scope of this experiment in terms of additional mode alternatives, trip purpose, and trip distance. It would be particularly important to consider slow modes as part of the choice-set in order to see the difference in perception of the new shared (automated) modes and walking and cycling. Also the important factors waiting time and travel time reliability were not included in the choice experiment. These could however prove to be quite influential for the perceived utility of FFCS and SAV, since for these modes a new dimension is added in this respect, namely the uncertainty of vehicle availability. Finally, future work could address the issue of the dominant alternative specific constants by including additional factors explaining the preference towards FFCS and SAV, such as trust in the new technology or the concept of reliability in regard to on-demand transport services.

Stated-choice experiments only provide a snapshot in time, collecting the perceived preferences of a group of respondents at the very moment of answering a set of questions and need to be carefully designed to minimize the risk of questions confusing, misleading or irrelevant to the respondents. It can therefore be regarded as the equivalent of an opinion poll that strives to elicit current preferences present in the target population. Notwithstanding, in the absence of large-scale deployments, stated-preference-studies are currently still the only source for a better understanding of the reception of self-driving vehicles and the different forms of transportation they could enable. Given the limitations inherent to research asking users instead of observing them, it is important to combine the findings from a multitude of such studies over time in order to be able to draw a reliable and holistic picture of the attitudes, preferences and perceptions. It is thus important to apply different models to different datasets to test whether a theory holds, which requires research to be repetitive and confirmatory.

The results presented in this study only allow examining how different user groups currently perceive freefloating car-sharing and shared automated vehicles for commuting purposes. It is likely that mode perception changes with the level of familiarity with it, therefore it will be necessary to continuously update mode choice preference of the different user groups towards new forms of shared mobility along with their introduction to the market. A series of attitudinal questionnaires accompanying gradually the introduction of the new vehicle technology and related new mobility services will allow future studies to monitor how the perceived utility of the new modes evolves over time with the increasing availability of large-scale free-floating car-sharing systems and shared automated vehicles.

\section{Acknowledgments \\ We thank Caspar Chorus, Bahamonde Birke, María Alonso González, and Sander van Cranenburgh for offering their kind advice on the set-up of the choice experiment and latent class models. An earlier version of this work has been presented at the Transportation Research Board 96th Annual Meeting.}

\section{Authors' contributions}

K.W.: Content Planning, Literature Search and Review, Survey Design, Model Estimation, Analysis and Interpretation, Manuscript Writing and Editing; O.C.: Idea Generation, Research Plan, Technical Contribution, Analysis and Interpretation, Manuscript Writing and Editing; K.M.: Research Plan and Editing; B.v.A.: Research Plan and Editing. The author(s) read and approved the final manuscript.

\section{Funding \\ The work of the first author is funded by the NWO TRAIL Graduate Programme.}

\section{Availability of data and materials}

The collected data of the stated-choice experiment has been made publicly available, with open access, at the 4TU.Centre for Research Data under the name "Stated Choice Experiment on Mode Choice in an Era of Free-Floating Carsharing and Shared Autonomous Vehicles: Raw Data" (https://data.4tu.nl/ repository/uuid:4ac4d7b7-c8b0-42ec-a096-55a4f1837585).

\section{Competing interests}

Not applicable.

\section{Author details}

${ }^{1}$ Delft University of Technology, Delft, the Netherlands. ${ }^{2}$ Technion - Israel Institute of Technology, Haifa, Israel. 
Received: 1 July 2019 Accepted: 15 April 2020

\section{Published online: 28 May 2020}

\section{References}

1. Alemi, F., Circella, G., Handy, S., \& Mokhtarian, P. (2018a). What influences travelers to use Uber? Exploring the factors affecting the adoption of ondemand ride services in California. Travel Behaviour and Society, 13, 88-104. https://doi.org/10.1016/J.TBS.2018.06.002.

2. Alemi, F., Circella, G., Mokhtarian, P., \& Handy, S. (2018b). Exploring the latent constructs behind the use of ridehailing in California. Journal of Choice Modelling, 29, 47-62. https://doi.org/10.1016/J.JOCM.2018.08.003.

3. Bahamonde-Birke, F., \& Ortuzar, J. (2015). About the categorization of latent variables in hybrid choice models, Discussion papers of DIW Berlin 1527, DIW Berlin, German Institute for Economic Research. https://doi.org/10.2139/ssrn. 2698095.

4. Bansal, P., Kockelman, K. M., \& Singh, A. (2016). Assessing public opinions of and interest in new vehicle technologies: An Austin perspective. Transportation Research Part C: Emerging Technologies, 67, 1-14. https://doi. org/10.1016/j.trc.2016.01.019.

5. Barbour, N., Menon, N., Zhang, Y., \& Mannering, F. (2019). Shared automated vehicles: A statistical analysis of consumer use likelihoods and concerns. Transport Policy, 80, 86-93. https://doi.org/10.1016/J.TRANPOL.2019.05.013.

6. Becker, F., \& Axhausen, K. W. (2017). Literature review on surveys investigating the acceptance of autonomous vehicles. Transportation 44, 1293-1306. https://doi.org/10.1007/s11116-017-9808-9.

7. Becker, H. Ciari, F. \& Axhausen, K. W. (2017). Comparing car-sharing schemes in Switzerland: User groups and usage patterns. Transportation Research Part A: Policy and Practice, 97, 17-29. https://doi.org/10.1016/j.tra.2017.01.004.

8. Bierlaire, M. (2003). BIOGEME: A free package for the estimation of discrete choice models. In Proceedings of the 3rd Swiss transportation research conference, Ascona, Switzerland.

9. Centraal Bureau voor de Statistiek (CBS). (2015). Huishoudens in bezit van auto of motor; huishoudkenmerken. Retrieved October 16, 2016, from statline.cbs. nl/StatWeb/publication/?WW=T\&DM=SLNL\&PA=81845NED\&LA=NL.

10. Centraal Bureau voor de Statistiek (CBS). (2016). Bevolking per maand; leeftijd, geslacht, herkomst, generatie. Retrieved June 13, 2016, from http:// statline.cbs.n|/Statweb/publication/?DM=SLNL\&PA=71090ned\&D1=0\&D2= $0-1 \& D 3=0,107,121-122 \& D 4=0 \& D 5=0 \& D 6=\mid \& H D R=T, G 3, G 1 \& S T B=$ $\mathrm{G} 2, \mathrm{G} 4, \mathrm{G} 5 \& \mathrm{~W}=\mathrm{T}$.

11. Centraal Bureau voor de Statistiek (CBS). (2018a). 4 Procent Lopend Naar Het Werk. Retrieved October 1, 2018, from https://www.cbs.nl/nl-nl/ nieuws/2018/14/4-procent-lopend-naar-het-werk

12. Centraal Bureau voor de Statistiek (CBS). (2018b). StatLine - Arbeidsverleden bevolking afgelopen 4 jaar, regio (indeling 2018). Retrieved September 16, 2019, from https://opendata.cbs.nl/statline/\#/CBS/nl/dataset/84460NED/ table?ts=1568635201654

13. Ciari, F., \& Axhausen, K. W. (2012). Choosing carpooling or carsharing as a mode: Swiss stated choice experiments. In Presented at 91st Annual Meeting of the Transportation Research Board, Washington, D.C (pp. 1-23).

14. de Luca, S., \& Di Pace, R. (2014). Modelling the propensity in adhering to a Carsharing system: A behavioral approach. Transportation Research Procedia, 3, 866-875. https://doi.org/10.1016/j.trpro.2014.10.065.

15. Delbosc, A., McDonald, N., Stokes, G., Lucas, K., Circella, G., \& Lee, Y. (2019). Millennials in cities: Comparing travel behaviour trends across six case study regions. Cities, 90, 1-14. https://doi.org/10.1016/J.CITIES.2019.01.023.

16. Ferrero, F., Perboli, G., Rosano, M., \& Vesco, A. (2018). Car-sharing services: An annotated review. Sustainable Cities and Society, 37, 501-518. https://doi.org/ 10.1016/J.SCS.2017.09.020.

17. Gkartzonikas, C., \& Gkritza, K. (2019). What have we learned ? A review of stated preference and choice studies on autonomous vehicles. Transportation Research Part C, 98(December 2018), 323-337. https://doi.org/ 10.1016/j.trc.2018.12.003

18. Greenwald, J. M., \& Kornhauser, A. (2019). It's up to us: Policies to improve climate outcomes from automated vehicles. Energy Policy, 127, 445-451. https://doi.org/10.1016/J.ENPOL.2018.12.017.

19. Haboucha, C. J., Ishaq, R., \& Shiftan, Y. (2017). User preferences regarding autonomous vehicles. Transportation Research Part C: Emerging Technologies, 78, 37-49. https://doi.org/10.1016/j.trc.2017.01.010.

20. Heinen, E., Maat, K., \& van Wee, B. (2013). The effect of work-related factors on the bicycle commute mode choice in the Netherlands. Transportation, 40(1), 23-43. https://doi.org/10.1007/s11116-012-9399-4.
21. Hess, S., Rose, J. M., \& Polak, J. (2010). Non-trading, lexicographic and inconsistent behaviour in stated choice data. Transportation Research Part D: Transport and Environment, 15(7), 405-417. https://doi.org/10.1016/j.trd.2010. 04.008

22. Hoogendoorn-Lanser, S., Schaap, N. T. W., \& OldeKalter, M.-J. (2015). The Netherlands mobility panel: An innovative design approach for web-based longitudinal travel data collection. Transportation Research Procedia, 11, $311-$ 329. https://doi.org/10.1016/j.trpro.2015.12.027

23. Jin, S. T., Kong, H., Wu, R., \& Sui, D. Z. (2018). Ridesourcing, the sharing economy, and the future of cities. Cities, 76, 96-104. https://doi.org/10.1016/ J.CITIES.2018.01.012

24. Kolarova, V., Steck, F., Cyganski, R., \& Trommer, S. (2018). Estimation of the value of time for autonomous driving using revealed and stated preference methods. Transportation Research Procedia, 31(November), 35-46. https://doi. org/10.1016/j.trpro.2018.09.044

25. Krueger, R., Rashidi, T. H., \& Rose, J. M. (2016). Preferences for shared autonomous vehicles. Transportation Research Part C: Emerging Technologies, 69, 343-355. https://doi.org/10.1016/j.trc.2016.06.015.

26. Ministry of Transport Public Works and Water Management. (2009). Cycling in the Netherlands. Retrieved from http://www.fietsberaad.n//library/ repository/bestanden/CyclingintheNetherlands2009.pdf

27. SAE International. (2018). Taxonomy and Definitions for Terms Related to Driving Automation Systems for On-Road Motor Vehicles. Retrieved from https://saemobilus.sae.org/content/j3016_201806

28. Shaheen, S., Bansal, A., Chan, N., \& Cohen, A. (2017). Mobility and the sharing economy: Industry developments and early understanding of impacts. In Low Carbon Mobility for Future Cities. Location: The Institution of Engineering and Technology (IET). UC Berkeley: Transportation Sustainability Research Center. Retrieved from https://escholarship.org/uc/item/96j5r729.

29. Spurlock, C. A., Sears, J., Wong-Parodi, G., Walker, V., Jin, L., Taylor, M., et al. (2019). Describing the users: Understanding adoption of and interest in shared, electrified, and automated transportation in the San Francisco Bay Area. Transportation Research Part D: Transport and Environment, 71, 283301. https://doi.org/10.1016/J.TRD.2019.01.014

30. Walker, J. L., Wang, Y., Thorhauge, M., \& Ben-Akiva, M. (2015). D-Efficient OR Deficient? A Robustness Analysis of SP Experimental Designs in a VOT Estimation Context. In Presented at the 94th annual meeting of the Transportation Research Board, Washington, DC (p. 18).

31. Wen, C.-H., Wang, W.-C., \& Fu, C. (2012). Latent class nested logit model for analyzing high-speed rail access mode choice. Transportation Research Part E: Logistics and Transportation Review, 48(2), 545-554. https://doi.org/10. 1016/J.TRE.2011.09.002

32. Yoon, T., Cherry, C. R., \& Jones, L. R. (2017). One-way and round-trip carsharing: A stated preference experiment in Beijing. Transportation Research Part D: Transport and Environment, 53, 102-114. https://doi.org/10. 1016/J.TRD.2017.04.009.

33. Young, M., \& Farber, S. (2019). The who, why, and when of Uber and other ride-hailing trips: An examination of a large sample household travel survey. Transportation Research Part A: Policy and Practice, 119, 383-392. https://doi. org/10.1016/J.TRA.2018.11.018.

\section{Publisher's Note}

Springer Nature remains neutral with regard to jurisdictional claims in published maps and institutional affiliations. 